\title{
El movimiento estudiantil argentino: aportes para una visión global de su evolución en el siglo $\mathrm{XX}$
}

\author{
Pablo Buchbinder \\ UBA - Conicet \\ pbuchbin@retina.ar
}

\section{Introducción}

Si bien el movimiento estudiantil ha sido desde principios del siglo XX un actor relevante de la vida política argentina, aún es dificil encontrar un trabajo de sintesis que indague en las variables centrales que orientaron sus estrategias y acciones en el largo plazo. En los últimos años se han incrementado de manera significativa los estudios especificos sobre su papel en distintos períodos. Artículos en revistas especializadas, libros colectivos e individuales, tesis de licenciatura, maestría y doctorado e incluso jornadas específicas como las que se realizan periódicamente desde hace casi dos décadas muestran la existencia de una rica y heterogénea producción sobre el tema. Sin embargo, más allá de los trabajos que publicaran hace ya varios años Rubén Levenberg y Daniel Merolla (1988), Gustavo Hurtado (1990), Ricardo Romero (1998) o las sintesis más acotadas y pretéritas de Richard Walter (1968), Bernardo Kleiner (1964) o Luisa Brignardello (1972), entre otras, aún se hace notar la ausencia de una aproximación a las tendencias de largo plazo que han signado la evolución de las organizaciones que agruparon y expresaron gremialmente a los jóvenes universitarios. Este breve texto tiene el propósito de esbozar algunas vías de análisis y plantear algunos problemas. Intentamos proponer puntos de referencia y clivajes para pensar las tendencias de evolución del movimiento estudiantil en un período extenso que va desde sus orígenes en la primera década del siglo XX hasta entrados los años 60. Un análisis de estas características presenta sin duda problemas y dificultades de saldar en un breve ensayo. Sólo tenemos la intención de proponer algunos ejes conceptuales que intentan ir más allá del estudio del discurso y la acción de las principales organizaciones.

(Archivos, año VI, $\mathrm{n}^{\circ}$ 12, marzo de 2018, pp. 11-32) 


\section{Los inicios}

La presencia de los estudiantes como actores diferenciados y con una fisonomía definida se advierte, tanto en Buenos Aires como en Córdoba, a lo largo del siglo XIX. Aún cuando constituían una parte muy minoritaria de la población de cada una de las ciudades, se distinguieron, tempranamente, por su presencia en el espacio público y, en más de una oportunidad, formando parte de movimientos que incidieron, significativamente, en la escena política. En 1865 al iniciarse la Guerra del Paraguay, los universitarios se organizaron y en bloque exigieron integrar un batallón que fue bautizado con el nombre de Manuel Belgrano. Una fuerte controversia sobre la reestructuración de la deuda pública los encontró en 1902 movilizándose en conjunto contra la propuesta elaborada por el ex presidente Carlos Pellegrini. El episodio marcó la ruptura del bloque conservador que gobernaba la Argentina desde 1880 y abrió la puerta a las transformaciones que culminaron con la sanción de la Ley Sáenz Peña. En estos años su presencia como grupo específico no pasaba desapercibida para quienes observaban la vida política, en especial en Buenos Aires.

En forma simultánea a su participación, a veces secundaria, como actores de la vida política en ambas ciudades, los estudiantes interactuaron de manera permanente tanto con las autoridades académicas como con los integrantes de los gobiernos provincial y nacional y, dentro de estos últimos, especialmente con los responsables del estado de situación de las casas de altos estudios. Un conjunto de motivos de controversia y conflicto entre estudiantes y miembros del gobierno universitario se fue delimitando con claridad desde las primeras décadas del siglo XIX.

Podría señalarse, con cierta arbitrariedad, que los reclamos se concentraban en cuestiones relativas al régimen disciplinario, a los sistemas y modalidades de examen y promoción, a los pagos de derechos de matrícula, pero también a las características de la enseñanza y a las acciones y conductas de miembros del cuerpo de profesores. Los estudiantes se organizaban informalmente para canalizar sus protestas sobre estos tópicos y si bien a menudo se encontraban con la indiferencia o la cerrada negativa frente a sus peticiones, también debe señalarse que hubo casos resonantes en los que estos fueron aceptados a veces por las mismas autoridades universitarias y, en algunos casos, también por los gobernantes que obligaron a aquellas últimas a aceptar los reclamos estudiantiles.

Dos ejemplos son, al respecto, particularmente ilustrativos. El primero es el acaecido a raíz del suicidio, en 1871, de un estudiante de Derecho de origen sanjuanino, Roberto Sánchez, a causa de la deshonra provocada por haber reprobado un examen. El otro, dos años después, 
involucró a José María Ramos Mejía, entonces un joven estudiante de Medicina de Buenos Aires que cuestionó en la prensa a las autoridades de la Facultad por aspectos relativos a la enseñanza. Estas le negaron la posibilidad de matricularse en el año posterior, lo que generó un movimiento de protesta estudiantil que, con el auxilio del gobierno, logró revertir la medida. En ambos casos los estudiantes se organizaron reclamando transformaciones sustantivas en el régimen de estudios, en los programas y en los procesos de selección de los profesores. En el segundo fue central, además, la exigencia de un cambio en el sistema de exámenes.

Hacia 1890 los pedidos estudiantiles en Buenos Aires, hasta entonces formulados de manera aislada, comenzaron a ser canalizados a través de una organización que cumplía, en principio, funciones relativas a la organización de la sociabilidad, pero que también articuló y expresó progresivamente cuestiones gremiales. Se trataba de la Unión Universitaria que agrupó a los estudiantes de las distintas facultades de la UBA. Una organización de carácter similar surgió luego en Córdoba. La aparición de los Centros de Estudiantes a partir de 1900 marca sin duda un nuevo punto de inflexión en la historia del movimiento estudiantil, aún cuando pueda observarse cierta continuidad en lo que respecta al tipo de reivindicaciones y reclamos.

La aparición de los centros se vincula con el incremento progresivo del número de estudiantes, con la necesidad de definir mejor las demandas, pero también con el propósito de dar un perfil más definido a las organizaciones y de precisar sus reclamos. Los centros establecieron, además, estrechas relaciones con las organizaciones que representaban a los profesionales. El caso del Círculo Médico Argentino y del Centro de Estudiantes de Medicina es ilustrativo al respecto. En 1908, finalmente, los estudiantes porteños fundaron la Federación Universitaria de Buenos Aires (FUBA).

\section{Los estudiantes}

Un análisis de los derroteros del movimiento estudiantil exige alguna aproximación a las características de la población universitaria, de su composición, origenes sociales, familiares, expectativas reunidas en relación con los estudios universitarios, culturas o mentalidades. Es aún mucho lo que ignoramos al respecto, si bien los trabajos de Luciana Carreño (2017: 79-106) publicados en los últimos años han realizado aportes sustantivos.

Podemos avanzar en este sentido, entonces, sólo a partir del conocimiento de algunas variables. En primer término: el número. Los universitarios constituian una parte extremadamente pequeña y privilegiada 
de la población. En 1918, en tiempos de la Reforma, sumaban entre 8 mil y 9 mil personas sobre cerca de 8 millones de habitantes. Los datos estadísticos que brindan las memorias elaboradas por los respectivos rectorados, sobre todo en Córdoba y Buenos Aires, muestran también que, aún cuando la Argentina era un país de inmigración y contaba con un elevado porcentaje de población extranjera, los estudiantes universitarios eran predominantemente argentinos. Por otra parte, la mayoría se concentraba en las Facultades de Derecho y Medicina.

¿Qué buscaban los jóvenes que acudian a estudiar en la Universidad? Responder esta pregunta nos lleva, en alguna medida, hasta las raíces coloniales de las instituciones universitarias. El papel que estas desempeñaron en el proceso de creación y consagración de las élites locales fue fundamental desde muy temprano. La corona española incentivó la fundación de universidades a lo largo de todo su período de dominación. El acceso a la burocracia civil o eclesiástica y la posesión de los cargos en las audiencias o en los cabildos catedralicios estaban a menudo supeditados a la ostentación de alguno de los títulos, ya fuese de bachiller, licenciado o doctor, que otorgaban las más de treinta universidades que fueron fundadas en Hispanoamérica durante la dominación española. De esta forma una verdadera élite "titulada" -especialmente desde mediados del siglo XVIII, cuando la venta de cargos fue progresivamente limitada- se superpuso con notables ventajas a otra signada por la riqueza material o por otro tipo de méritos, como los militares. $\mathrm{El}$ acceso a la carrera burocrática ofrecía prestigio, poder, e ingresos seguros en un mundo signado por la imprevisibilidad. La aspiración a obtener un título universitario era sobre todo visible en los sectores de la llamada "gente decente" pero sin recursos. Los casos de Juan Bautista Alberdi, miembro de la élite tucumana favorecido con una beca para estudiar en Buenos Aires, y de Domingo F. Sarmiento, oriundo de San Juan a quien ese mismo favor le fue negado constituyendo una marca que arrastraria de por vida, son ejemplos contundentes.

La construcción de una verdadera élite distinguida y privilegiada específicamente por sus títulos fue promovida y amparada por los estados sudamericanos luego de los procesos revolucionarios y las guerra civiles, y sobre todo a partir de la consolidación nacional en la década de 1880 . Se les otorgó a las universidades el monopolio en la concesión de los títulos, sobre todo de aquellas profesiones esenciales para la reproducción social, como las de médico y abogado. También se les cedió el derecho de conceder las reválidas de los títulos emitidos en el exterior. Además, desde el Estado se vigiló celosamente el ejercicio ilegal de estas profesiones. De este modo se construyó un lazo estrecho entre los mismos Estados, las universidades y las profesiones. Ese mismo monopolio y la condición elitista de la formación superior otorgaron no 
solamente un grado de prestigio notable a los profesionales universitarios, sino también ingresos muy elevados. Esto provocó que el acceso a los títulos universitarios cumpliese un papel central en los procesos de movilidad de la dinámica sociedad argentina de principios de siglo.

Es muy posible que los inmigrantes y sus hijos incorporasen estas nociones provenientes, en gran medida, del mundo hispánico. Pero aún estando la Argentina dominada por una oligarquía universitaria, como señalaría el publicista Emilio Becher (1906) en La Nación, el acceso a los altos estudios no estuvo totalmente cerrado por motivos étnicos o de origen, sobre todo en el caso de Buenos Aires. La experiencia de Enrique Dickmann (1930), narrada en sus Recuerdos de un militante socialista, muestra que las posibilidades de realizar una carrera exitosa en estas instituciones estaban abiertas también para los inmigrantes recientes y sin recursos que contaban, de todos modos, con una base adquirida a partir, muy probablemente, de la práctica religiosa.

No es extraño entonces que el tema del acceso a los títulos constituyese el trasfondo de gran parte de las luchas gremiales de los primeros centros de estudiantes. Sus movilizaciones se construyeron a partir de una serie de protestas dirigidas contra las medidas que los consejos que gobernaban las universidades, y sobre todo las facultades, oponian en el camino que los llevaba al ansiado título profesional. Regímenes de asistencia a exámenes, correlatividades, derechos de matrícula, constituyeron campos en torno a los cuales se configuraron las primeras reivindicaciones. Las mismas elites que gobernaban la universidad y el país buscaban de algún modo regular el acceso a aquellos mecanismos que, a su vez, eran centrales en la integración de las mismas clases dirigentes. En 1903 y 1905 se produjeron una serie de agudos conflictos en las Facultades de Derecho y Medicina de la Universidad de Buenos Aires (UBA) que tuvieron un notable impacto a nivel nacional. En el primer caso el conflicto se originó a raíz de una serie de medidas relativas a la implementación de turnos de examen y sistemas de clasificaciones. En el segundo estuvo vinculado con la conformación de la terna para la designación de un profesor titular. Las protestas estudiantiles, que encontraron una férrea oposición en la dirigencia universitaria, tuvieron en cambio una recepción positiva en el Congreso, en la prensa y entre los integrantes del mismo Poder Ejecutivo. Como resultado de estas movilizaciones, la UBA reformó su estatuto en 1906, suprimiendo los cargos vitalicios en los consejos que gobernaban las facultades y estableciendo ahora su elección -indirecta- por el cuerpo de profesores.

En este contexto se impone también otra pregunta fundamental, que es la de la relación del movimiento estudiantil con la política nacional y local. Si bien como señalamos, los estudiantes se involucraron como cuerpo ya desde el siglo XIX en distintos eventos políticos, en líneas 
generales parecen compartir cierta actitud de indiferencia hacia los problemas de la vida cívica. Los estudiantes, aún cuando las universidades constituían el principal lugar de socialización y reclutamiento de las elites políticas, preferian, en su gran mayoría, permanecer ajenos a los problemas centrales de la vida pública. La elección de temas de tesis en la Facultad de Derecho de la UBA muestra, por ejemplo, el interés de los futuros abogados por problemas relacionados, fundamentalmente, con temáticas del Derecho Civil y Comercial y escasa predilección por las cuestiones vinculadas con el Derecho Politico, Constitucional o Administrativo. La limitada atención que los estudiantes prestaban a las variables de la política nacional no pasaba inadvertida incluso a algunos de sus dirigentes. Una nota en la Revista del Centro de Estudiantes de Derecho en 1914 señaló que los universitarios porteños "no nos hemos distinguido, por lo menos en estos últimos años, por nuestros entusiasmos políticos". Se sostenía además que "especialmente entre los alumnos y recién egresados de nuestra Facultad era notable esa indiferencia". Por eso se celebraba la convocatoria a un encuentro por parte de un recién egresado, alumno brillante, distinguido además por su participación en la vida institucional del Centro, a quienes simpatizasen con los ideales de la Unión Cívica Radical.

\section{La Reforma}

El período que se abrió en 1914, como en otras muchas dimensiones de la vida política y social argentina, modificó de manera intensa la situación estudiantil y sus relaciones con las autoridades universitarias y gubernamentales. Los problemas de muchos estudiantes para sostenerse económicamente se agravaron a raíz de la crisis producida por la guerra. Documentación conservada en el archivo de la UBA muestra un incremento sustantivo de los pedidos de exención de derechos de matrícula durante estos mismos años, sobre todo provenientes de estudiantes del interior. A la vez, la sanción de la ley Sáenz Peña y el ascenso de la UCR al gobierno conllevaron cambios sustantivos en el clima político a nivel nacional que contrastaban en alguna medida con la situación no sólo en diversos ámbitos provinciales, sino también en instituciones universitarias como la de Córdoba, donde los miembros de los cuerpos directivos tenían carácter vitalicio y conservaban la atribución de designar a los nuevos miembros ante casos de renuncia o fallecimiento. El uso sistemático que el gobierno de Yrigoyen hizo de la intervención federal abría nuevos caminos no sólo para la modificación de situaciones provinciales, sino también en el ámbito universitario.

Además, los estudiantes se encontraron inmersos en un clima de conflictividad social creciente en el que la confluencia con otros sectores 
afectados por la crisis, en particular los obreros industriales, se hizo evidente. La Revolución Rusa, el fin de la Primera Guerra Mundial y los procesos revolucionarios que conmovieron al mundo hasta principios de los años 20 tuvieron, además, un impacto significativo en el mundo político argentino y entre los estudiantes, aun cuando sus efectos fueran diluyéndose a lo largo de esa década.

1918 fue el año de la Reforma Universitaria, resultado esencialmente de la movilización y presión estudiantil. Ningún análisis de este acontecimiento fundacional en la historia universitaria argentina puede obviar el examen contemporáneo de la situación política, social y universitaria del país, como también la de la misma provincia de Córdoba, signada históricamente por el enfrentamiento entre liberales y clericales (Moyano, 2010: 107-155). Las condiciones que llevaron al desencadenamiento de la rebelión estudiantil en Córdoba han sido extensamente tratadas. Es significativo, de todas formas, tener presente que en Córdoba regian en 1918 prácticamente los mismos estatutos sancionados en la década de 1880. A diferencia de Buenos Aires, donde la presión estudiantil había logrado a principios de siglo la transformación de los estatutos, eliminando el gobierno vitalicio de los académicos y otorgando mayor peso al cuerpo de profesores, en la provincia mediterránea todos los ensayos similares habian fracasado. La pregunta que se impone aquí está relacionada con los factores que impidieron transformaciones graduales de la estructura universitaria. Las respuestas son diversas. Algunos la han atribuido a la fuerza de los grupos clericales instalados tanto en el gobierno provincial como en la universidad. Interpretaciones de fines de los años 60, como las de Juan Carlos Agulla (1968) han destacado sobre todo el peso de la universidad en la construcción de las elites políticas cordobesas. Estas se definían esencialmente por su condición doctoral, razón por la que cualquier transformación de la estructura politica de Córdoba debía ser previamente una reforma universitaria. El Comité Pro-Reforma de los estudiantes cordobeses se constituyó solicitando al gobierno de Yrigoyen la intervención a la universidad. Proclamó inicialmente su neutralidad en términos políticos y religiosos, y luego de un fuerte debate interno señaló las incongruencias de la estructura de gobierno de la universidad, caracterizada por el predominio de consejeros vitalicios que se autorreclutaban, con los cambios políticos que el país había experimentado desde 1916.

También es fundamental tener en cuenta que la Reforma impulsó la organización gremial estudiantil en una nueva escala. A la creación de la Federación Universitaria de Córdoba, se sumó tiempo más tarde la de la Federación Universitaria Argentina (FUA). Esta inauguró su Primer Congreso entre los días 20 y 31 de julio de 1918. Cabe detenerse brevemente entonces en su análisis. En principio es posible subrayar 
que el tono de los debates y de las propuestas fue considerablemente más moderado del que, como podremos ver mas adelante, se expresó en publicaciones estudiantiles contemporáneas. Fue presidido por Osvaldo Loudet, electo luego presidente de la organización, quien, en su discurso inaugural, sostuvo de manera enfática que "todo" era "ajeno a él menos las cuestiones de pedagogía superior y que todas ellas iban a ser resueltas con espíritu científico", poniendo así coto a los intentos de politizar los debates y discusiones. Al referirse a la Reforma la conceptualizó como un movimiento de renovación de valores "intelectuales y morales". En líneas generales, el tono de los discursos y las propuestas fueron consistentes con la impronta que marcó Loudet desde el inicio. Los representantes de las cinco universidades (a las tres nacionales se sumaron los de Santa Fe y Tucumán, entonces provinciales) se ocuparon particularmente de cuestionar las orientaciones generales de la vida universitaria argentina, denunciaron el atraso de las instituciones y manifestaron la necesidad de su renovación, en un tono que recuperaba la impronta americanista que caracterizó los discursos de los líderes cordobeses. Probablemente, los pronunciamientos más contundentes fueron los relativos al gobierno universitario. En el proyecto de ley debatido inicialmente, la autonomía de las casas de estudios fue asumida como un presupuesto, pero se insistió sobre todo en el principio de la participación estudiantil en el gobierno. La base de estos juicios estaba vinculada con la idea de que la universidad debía ser una república democrática regida por un gobierno compuesto por un número similar de representantes diplomados, estudiantes y profesores. Sin embargo, la idea de la participación igualitaria de los tres claustros fue sustituida en las resoluciones oficiales por otra que dejaba la cuestión de la proporción librada a lo que se resolviese en cada casa de estudios. Tampoco propuso innovaciones significativas en lo referente a la elección de los profesores, que seguía en manos del Poder Ejecutivo que decidia en base a ternas elevadas por las universidades. Se pronunciaron por la docencia libre y por la asistencia libre a clase, denunciando la generalizada mediocridad del cuerpo de profesores. Criticaron la orientación profesionalista de la educación superior y postularon la necesidad de la creación de la casa del estudiante, el intercambio de profesores y alumnos a escala nacional e internacional. Finalmente, propusieron estimular las actividades de extensión, comprometiendo a los estudiantes en campañas colectivas contra el analfabetismo.

Si bien rechazaron las críticas de aquellos que se preocupaban por el aumento, en este caso, del número de estudiantes, y consecuentemente del de profesionales, no postularon la supresión de los exámenes de ingreso. El proyecto quizás más disruptivo que se presentó fue el que pretendió asegurar la gratuidad de la enseñanza universitaria sobre la 
base de imponer cargas adicionales a los propietarios ausentistas. Fue presentado por Gabriel del Mazo y Dante Ardigó, pero fue rechazado por 21 votos contra 19. La FUA inició entonces su camino sobre la base de una contundente crítica al estado de situación de las casas de altos estudios y con un fuerte pronunciamiento a favor de la participación de los estudiantes en el gobierno universitario. Pero su tono fue claramente moderado y su relación con los partidos políticos distante, no pronunciándose sobre aspectos de la situación general del país.

Sin embargo, el Congreso no expresó necesariamente las orientaciones del movimiento estudiantil en su conjunto. El reformismo fue la cuna de expresiones politicas y culturales heterogéneas. Los derroteros e itinerarios de los reformistas y sus discípulos fueron muy diversos. En parte es posible seguir examinándolos en la amplia serie de publicaciones, y sobre todo de revistas, que sectores surgidos del movimiento del 18 editaron en esa década tan prolífica del 20. Natalia Bustelo (2015) ha llevado a cabo un recorrido exhaustivo por las publicaciones surgidas del movimiento reformista que muestra la diversidad -aun dentro del heterogéneo campo de las izquierdas- en términos de proyección intelectual y politica que siguieron un conjunto de expresiones surgidas de los sucesos del 18. De todas formas, creemos que un breve repaso de dos publicaciones especialmente significativas surgidas en este contexto permite una primera aproximación a esta cuestión.

Veamos entonces, en primer término, La Gaceta Universitaria. Editada por los estudiantes rebeldes de Córdoba, posibilita cierta visión del mundo de referencias ideológicas de quienes iniciaron el movimiento del 18. Aquí se publicó por primera vez el "Manifiesto liminar", documento fundacional de la Reforma. La revista pasó al menos por dos etapas claramente diferentes. La inicial abarca los doce primeros números, publicados durante el año 1918. El tono tiende más a subrayar los aspectos corporativos y específicamente universitarios. En sus primeros números reclamaba para sí misma la condición de una publicación que, como el movimiento que la inspiraba, era más bien neutral en los aspectos políticos y religiosos. Esta orientación se fue modificando, en particular después de los episodios de junio de 1918, cuando el movimiento se radicalizó a raíz del fracaso en erigir a su candidato, Enrique Martínez Paz, como rector de la universidad. A partir de entonces, la confrontación con el profesorado y una parte significativa de la clase dirigente cordobesa le dio una tonalidad distinta.

Durante 1919, en que se publicaron los últimos números, la revista tomó un tono diferente. Allí el pronunciamiento sobre las cuestiones de la política nacional e internacional fue más claro. En este sentido es también fundamental prestar atención al contexto específico. La sociedad argentina de principios de siglo era, como han destacado diversos 
autores, una comunidad dotada de alto grado de dinamismo y movilidad y en la que primaba un imaginario estrechamente vinculado con la posibilidad real y concreta del ascenso social. Sin embargo, estos principios estaban en crisis desde el inicio de la guerra y en particular durante este año. El descontento social, en particular el obrero y popular que se expresó entre otros episodios en la llamada "Semana Trágica" de 1919, muestra claramente ese clima. La conformación de una organización que actuó como fuerza de choque de los sectores más conservadores, como fue La Liga Patriótica, y la revitalización de las leyes represivas y xenófobas sancionadas a principios de siglo, como las de Residencia y Defensa Social, marcaron esos años más allá del también significativo impacto de la situación internacional. Los estudiantes se pronunciaron, a través de La Gaceta, en forma explícita contra aquella organización y por la derogación de las leyes mencionadas. Cuestionaron con dureza, además, la xenofobia y el antisemitismo.

Pero aún así cabe señalar que las referencias ideológicas y políticas que son posibles advertir en la revista -aún dentro del campo ideológico de la izquierda- son variadas. Una de ellas es la del economista norteamericano Henry George. La difusión que el pensador de origen español pero radicado en la Argentina, Cándido Villalobos Domínguez (1919), hizo de esta obra fue registrada particularmente. Villalobos señalaba la necesidad de diferenciar entre el capital productivo y el rentístico, proponiendo avanzar gradualmente en la eliminación de este último. Las implicancias en términos de políticas impositivas y de avance sobre las estructuras latifundistas ejercieron un gran atractivo entre los estudiantes cordobeses.

La otra referencia fundamental para los estudiantes cordobeses era el ideólogo y líder del sindicalismo revolucionario, Georges Sorel. La revista se pronunció en estos años de manera contundente contra el reformismo socialista, pero la opción ante éste no era el bolchevismo, sino justamente Sorel.

Por otro lado, los estudiantes fueron muy claros en sus pronunciamientos frente a la situación internacional. Condenaron la guerra contra Rusia, a la que consideraron parte de una operación criminal, pero también se pronunciaron contra la paz de Versalles. Advirtieron sobre el recrudecimiento del conflicto social y la lucha de clases a nivel nacional e internacional, pero sus referencias politicas e ideológicas siguieron siendo eclécticas. Priorizaban la defensa de la lucha por la paz en un arco que unía cierta tímida y contradictoria defensa de la figura de Jean Jaurès con la de Rosa Luxemburgo. En las críticas a la desigualdad y a la explotación de los trabajadores tomaban como fuentes de referencia a la figura de Marx, pero también a la de León XIII, el papa autor de la encíclica Rerum novarum. 
Una publicación posterior como Inicial también puede ser examinada en este contexto. Se publicó entre octubre de 1923 y febrero de 1927. Fue editada por un núcleo de antiguos estudiantes que ejercieron su militancia en los centros de las facultades de Filosofia y Letras y Derecho de la UBA, aunque dos de sus editores venían de Córdoba. Los trabajos publicados aquí muestran una complejidad mayor de la que es posible observar en La Gaceta. Se cruzan la reflexión estética y la crítica literaria con el análisis político. Fueron críticos de la experiencia soviética, subrayando sobre todo el costo social de la estabilización, la conformación de un aparato político-burocrático y el ejercicio de la violencia hacia la población. En este contexto, los redactores de Inicial opusieron a Lenin con los anarquistas. El primero había convertido a la revolución en una oleada brutal signada por crimenes inicuos. Nuevamente aparece con fuerza un aspecto que ya estaba contenido en la publicación analizada anteriormente: la contraposición entre la tradición revolucionaria rusa y la que encarnaba el sindicalismo revolucionario inspirado en Sorel. Se trata de un contexto signado por una fuerte crítica al legado de Marx y a la construcción de lo que se denomina "El Vaticano ruso". También aquí aparece un motivo habitual en la revista que es la celebración por la crisis, por la decadencia y destrucción de los ideales políticos y democráticos burgueses que contrasta con la más débil preocupación por la crisis del sistema capitalista.

Mas allá de matices y diferencias internas que dieron lugar a un conjunto diverso de agrupaciones, ya a finales de los años 20 el reformismo fue consolidando su identidad en base a la defensa del laicismo, el americanismo, el protagonismo de la juventud, las críticas a la universidad "doctoral" y profesionalista y la solidaridad con las luchas y reivindicaciones de la clase obrera.

\section{Los estudiantes en los organismos de gobierno universitarios}

Pero el análisis de las publicaciones estudiantiles o las revistas requiere ser complementado con otro tipo de fuentes, a los efectos de una reconstrucción adecuada de las tendencias y orientaciones del movimiento. En este sentido, no es posible prescindir de un estudio en profundidad de las acciones llevadas a cabo por los representantes de los estudiantes, a menudo profesionales o graduados recientes, en los Consejos Directivos y en el Consejo Superior de las casas de altos estudios. Cualquier análisis de los derroteros del movimiento estudiantil debe ser complementado con un examen en profundidad de los reclamos elevados colectivamente por los Centros de Estudiantes o por los mismos Consejeros, que pueden rastrearse en los mismos archivos o 
en las actas. En este sentido, cabe destacar que durante los 20, incluso luego de los cambios estatutarios promovidos desde el gobierno de Alvear en 1923, predomina un tono claramente corporativo y una clara continuidad con el tipo de reclamos que las mismas organizaciones gremiales estudiantiles venían efectuando desde la segunda mitad del siglo XIX. Pero la diferencia es que esos reclamos eran atendidos ahora con una mayor deferencia, producto, sin duda, del peso que los nuevos estatutos otorgaron a los estudiantes en el gobierno de las casas de estudios. Exigencias de separación o recusación de profesores en mesas de examen, pedidos de postergación de exámenes o establecimiento de nuevos turnos, solicitudes de exención o postergación de pago de matrículas, o la oposición a medidas limitacionistas en el ingreso a algunas facultades, signaron los ejes de la acción estudiantil.

Los representantes estudiantiles -graduados o profesores universitarios- en acuerdo, a menudo, con miembros de las corporaciones profesionales lograron incidir en los procesos de formación de las ternas a partir de las que el Poder Ejecutivo elegia a los profesores titulares, y también en la designación de los suplentes. Además lograron modificaciones sustantivas en aspectos tales como regímenes de examen o de asistencia a clase. Mas allá de algunas modificaciones menores en los estatutos que limitaron su representación, sobre todo desde 1923, conservaron una importante y a menudo también decisiva capacidad de incidencia en los organismos de gobierno universitarios, concentrándose en aspectos vinculados específicamente con la vida académica. Pero esta tendencia a privilegiar lo gremial y corporativo generó también tensiones y fuertes polémicas. Los años 20 vieron así al movimiento estudiantil fragmentarse. La Reforma fue objeto de debate y controversias en parte por haber perdido gradualmente su impetu inicial que, en algunos casos, fue explicado, sobre todo desde principios de los años 30, por no haber logrado una proyección adecuada en la arena política y social y constreñirse excesivamente al campo universitario.

Agrupaciones criticas de las orientaciones dominantes del reformismo surgieron durante estos años y también a lo largo de la década del 30. Grupos de estudiantes cercanos al Partido Comunista crearon la organización Insurrexit, que tuvo una primera expresión a principios de los años 20, disolviéndose rápidamente, y luego otra al comenzar la década siguiente. Sobre todo la segunda, liderada por Héctor Agosti y conformada en el marco de la estrategia de clase contra clase de la Tercera Internacional, fue muy crítica con la pasividad del reformismo y su incapacidad para articular proyectos con impacto y alcance en la política nacional. Pero ese mismo tipo de críticas las formularian algunos antiguos líderes del 18, como el mismo Deodoro Roca (2008), quien al observar a principios de los 30 el fracaso de las transforma- 
ciones en el mundo universitario, aún signado por la mediocridad y el peso de las orientaciones profesionalistas, afirmaría que el problema fundamental estaba en las limitaciones de la Reforma para proyectarse como Reforma Social.

Otra variable que debe observarse aquí es que los intentos de construir un partido político derivado de la experiencia del movimiento estudiantil, como fue el APRA en Perú, fracasaron en la Argentina. A mediados de los 20 se conformó en la Facultad de Derecho de la UBA el Partido Reformista Centro Izquierda liderado, entre otros, por Julio V. González y Carlos Sánchez Viamonte. Se opusieron -infructuosamenteal intento de la mayoría de los profesores de la Facultad de Derecho de consagrar como decano al dirigente conservador (más tarde Presidente de la Nación), Ramón Castillo. Lo hicieron impugnando sobre todo su pensamiento en términos universitarios, en particular su negativa a admitir el principio de la autonomía universitaria y fundamentalmente por concebir a la Facultad de Derecho como una institución profesionalista, dedicada a estudiar y enseñar sólo aspectos vinculados con la práctica de la abogacía y no como un instituto abocado además, y prioritariamente, a la alta cultura y los estudios desinteresados.

El fracaso en el proceso de constitución de un Partido de la Reforma merece una explicación un tanto más compleja. Quizás la primera de ellas deba atender sobre todo a su mismo éxito. Amparada por el gobierno de Hipólito Yrigoyen, sus principales reivindicaciones fueron parcialmente satisfechas. Aún con los retrocesos que se vivieron desde el año 23 -calificados por algunos como parte de una verdadera contrarreforma- y desde los 30, la influencia estudiantil en el gobierno universitario se mantuvo -con matices- hasta mediados de la década siguiente. Fue la consistencia con el orden politico vigente la que hizo posible el éxito y la supervivencia de la Reforma en el medio universitario y, al mismo tiempo, la diferenció de expresiones similares en otros países, en particular en Cuba o Perú, donde el movimiento estudiantil se proyectó como tal en la escena política, radicalizándose rápidamente. El movimiento de la Reforma y sus expresiones estudiantiles -a pesar de los claros posicionamientos de izquierda de algunos de sus integrantes- no fueron percibidos por sectores de la elite dominante como una amenaza sustantiva y estructural al orden social y político. Tal vez la experiencia uruguaya, donde los estudiantes tenían representación en el gobierno universitario desde 1908, haya incidido al respecto.

\section{La "década infame"}

Los años 30 marcaron el inicio de ciertos cambios en la orientación del movimiento estudiantil y su relación con la política, aunque estos no 
fueron estructurales. La FUA se pronunció luego del golpe de manera contundente contra la dictadura, aun cuando algunos de sus integrantes habian exigido dias antes la renuncia de Yrigoyen e incluso formaron parte de la caravana de los sublevados. La persecución del gobierno militar y de los gobiernos de la llamada "década infame" se centró sobre todo en los militantes comunistas. En 1936, el diputado Matías Sánchez Sorondo presentó un proyecto de ley de defensa contra el comunismo en el que señaló a la FUA como una institución bolchevique. Esta última habia entrado a fines de los 20 en una crisis interna, pero los efectos del golpe militar en la universidad impulsaron su reconstrucción poco después. Si bien siguieron manteniendo una perspectiva crítica de la experiencia radical, cuestionaron duramente a la dictadura uriburista primero y luego a las orientaciones conservadoras de los gobiernos subsiguientes. La defensa de la participación estudiantil en el gobierno universitario -amenazado por los estatutos reaccionarios de la década del 30- y luego del principio de la autonomía fueron elementos que galvanizaron la acción de las organizaciones. La resistencia y las protestas por la persecución por razones políticas a estudiantes y docentes, sobre todo en facultades como la de Derecho de la UBA, en esos mismos años conformaron también ejes de las movilizaciones y protestas.

El peso de los sectores afines a la izquierda, tanto la relacionada con el Partido Comunista como con el Socialista, fue muy claro en el congreso de la FUA celebrado en 1932, como lo sería también en el realizado diez años más tarde. Las resoluciones tomadas en el primero de los mencionados partian del reconocimiento de la crisis de la sociedad capitalista señalando que la guerra, el imperialismo y la opresión de los pueblos eran el resultado de la organización social vigente y que sólo desaparecerian con el "advenimiento de una sociedad ordenada por la economía colectiva y el derecho social". En convenciones y encuentros previos al congreso se habia propuesto ya la asociación con las organizaciones obreras, y el repudio al militarismo y al imperialismo, pero también hubo aquí otros pronunciamientos sobre aspectos universitarios como el que, ya positivamente, exigía la gratuidad de la enseñanza. Durante la segunda mitad de los 30, en el marco del clima de persecución organizado desde el gobierno y el Estado y centrado fundamentalmente en los militantes comunistas, fue cobrando peso la consigna de la defensa de las libertades democráticas. En el congreso de 1942 fue claro e inequívoco el pronunciamiento contra el avance del fascismo.

Pero, nuevamente, la pregunta que se impone aquí es si estas tendencias visibles en los pronunciamientos de las FUA se traducen en cambios sustantivos en las estrategias de los representantes estudiantiles en los ámbitos del gobierno universitario. Parecería en principio que sólo muy parcialmente, lo que llevaria a críticas como las ya mencionadas 
de Deodoro Roca. La escisión de las perspectivas gremiales y políticas continuó. La universidad en este contexto se desenvolvió, como hemos señalado, con un relativo grado de autonomía. El tono moderado que adquirió el movimiento estudiantil en algunas facultades de la UBA, luego conocidas por la presencia de grupos de estudiantes radicalizados, como sucedió en Filosofia y Letras, fue señalado por el militante del Partido Comunista Héctor Agosti (1965), quien en los años sesenta recordaba el carácter extremadamente "sosegado" del reformismo.

El proceso de burocratización e incluso de corrupción de la dirigencia estudiantil en los años 30 y los 40 fue evidente y provocó algunos escándalos de amplia repercusión pública como el que, justamente, inició el ex presidente de la FUA, Osvaldo Loudet, siendo ahora vicedecano de la Facultad de Medicina durante 1943. Loudet acusó a los representantes estudiantiles en los consejos de establecer acuerdos con sectores del claustro de profesores a través de diversos mecanismos con el propósito de favorecer a determinados candidatos a cargos de profesor. Dejaba entender también que las negociaciones incluian favores para distribuir en los dos términos de la relación. Las acusaciones promovieron una investigación ordenada por el Consejo Superior y una fuerte réplica de uno de los representantes estudiantiles reivindicando los principios de la Reforma y la capacidad de los representantes estudiantiles para intervenir en decisiones como estas. De todas formas, este episodio incidió en la erosión de la imagen pública de la universidad y del movimiento estudiantil que quedó fuertemente desprestigiado.

\section{E1 peronismo}

La experiencia del peronismo y los efectos de su política universitaria provocaron cambios sustantivos y ahora sí estructurales en los modos de acción del movimiento estudiantil. Modificaron sus estrategias y alteraron sustancialmente los modos en que se desenvolvian las relaciones entre universidad y vida política. Las intervenciones universitarias en la Universidad del Litoral, primero, a cargo de Jordán Bruno Genta y luego las que, masivamente, se realizaron en todas las instituciones desde noviembre de 1943, la supresión de la autonomía y los intentos de confesionalizar la enseñanza universitaria fueron colocando al movimiento estudiantil en la oposición frontal al gobierno militar, actitud que se trasladó luego a la candidatura presidencial de su heredero forzoso, Juan Domingo Perón. Como han destacado Levenberg y Merolla, los reformistas asumieron gran parte de la organización de la Unión Democrática. Daniel James (1987), por su parte, ha señalado la hostilidad que manifestaron quienes se movilizaron por la libertad de Perón el 17 de Octubre frente a las instituciones de enseñanza superior. Su victoria 
electoral llevó a una nueva intervención luego de un breve período de normalización y a la construcción de un nuevo régimen universitario a través de leyes específicas que desconocieron el principio de la autonomía y limitaron, en este marco, la participación estudiantil en el gobierno universitario.

Las organizaciones estudiantiles surgidas desde principios de siglo, las federaciones y los centros, ámbitos en los que confluian desde liberales hasta comunistas, debieron actuar durante estos años en una situación de semiclandestinidad y se unieron en la oposición más allá de diferencias específicas consolidando su identidad reformista. Pero también debemos señalar que, tiempo más tarde, el reformismo comenzó a ser de algún modo cuestionado, a partir de la aparición de una nueva agrupación: el humanismo. Este congregó a grupos católicos que se diferenciaron desde un inicio de los sectores nacionalistas de derecha que avanzaron en el control de las instituciones educativas a partir del golpe del 43 y que mantuvieron cuotas relevantes de poder en el ámbito universitario durante el peronismo. Los humanistas concitaron la adhesión de sectores importantes del estudiantado. Si bien se diferenciaron del Reformismo, mantuvieron una perspectiva crítica del peronismo. A esta primera división se sumaron otras menores y coyunturales, como las que separaron a los comunistas del resto del espectro reformista en el momento en que aquellos, temporalmente, decidieron unirse a la Confederación General Universitaria (CGU), la organización estudiantil amparada por el gobierno de Perón.

La experiencia de la CGU muestra las limitaciones que el peronismo encontró a la hora de construir una organización sólida que lo representase entre el estudiantado universitario, lo que de algún modo revela la fuerza que todavia conservaba la identidad reformista. Finalmente, se constriñó a congregar a un número reducido de estudiantes que, en muchos casos, eran también miembros del claustro no docente.

El impacto del ascenso del peronismo sobre el movimiento estudiantil fue sustantivo y debe observarse en diversos planos. En principio situó al problema de la defensa de la autonomía universitaria en un lugar central. El tema no había estado ausente en la agenda del movimiento estudiantil en el período anterior, pero nunca había ocupado un lugar fundamental entre sus preocupaciones porque desde la constitución del sistema académico moderno en la década de 1880 hasta mediados de 1940, con excepciones marcadas obviamente en los periodos de gobierno militar e intervenciones, la universidad habia conservado cuotas relativamente considerables de autonomía. El peronismo quebró de manera radical con esta situación, colocando el tema en un lugar central de la agenda.

Durante el peronismo el sistema universitario experimentó además 
transformaciones significativas cuyos efectos se hicieron sentir en el mediano plazo. Un aspecto fue el aumento sustantivo de la matrícula, que prácticamente se triplicó. Este fue el período que asistió al inicio de la conformación del sistema universitario de masas en la Argentina. Desde entonces el crecimiento del número de estudiantes fue constante hasta que lo clausuró -temporalmente- la política de ingreso de la dictadura instaurada en 1976. Estos cambios, que se insertan en un tendencia global, fueron resultados de transformaciones en las condiciones generales de vida que acompañaron los años posteriores a la Segunda Guerra Mundial. Pero sin duda, esta tendencia fue fortalecida con la decisión de asegurar la gratuidad de los estudios superiores, dispuesta por el gobierno de Perón en 1949, y el levantamiento durante algunos años de las restricciones al ingreso. Esto provocaría que, en los años subsiguientes, la agenda de los problemas universitarios se volviese más compleja y pasase a incluir, en un lugar central, nuevas demandas como el tema presupuestario, que pasó a ocupar aquí un papel fundamental.

\section{La Revolución Libertadora y los años 60}

El protagonismo que adquirieron los estudiantes en la lucha contra el gobierno peronista les otorgó una percepción particular sobre su papel central en la constitución de un futuro orden universitario. Este papel le fue reconocido a las organizaciones estudiantiles por las autoridades del gobierno de facto que derrocó a Perón en 1955, que permitió que el nuevo rector de la UBA fuese designado a partir de una terna de candidatos sugeridos por los mismos estudiantes. José Luis Romero, historiador y reconocido militante socialista, y además el preferido por aquellos, fue el elegido. El nuevo orden universitario, derivado de los presupuestos contenidos en el decreto-ley 6.403 del gobierno militar reconoció la autonomía universitaria en un grado mucho más amplio que el previsto en las normativas de fines del siglo XIX, que fue también el que rigió en tiempo de la Reforma. Fue fundamental, en ese sentido, el hecho de que las nuevas normas permitieran que las universidades pudiesen seleccionar a sus docentes a través de concursos, a diferencia de lo que establecía la ley Avellaneda que otorgaba esa potestad al Poder Ejecutivo. Además, obviamente, aseguró la representación estudiantil junto a la de los graduados y profesores en el gobierno universitario.

El reformismo adquirió y reforzó su identidad, en principio, a partir de entonces sobre la base de la defensa de la autonomía y el cogobierno. Pero también en base a la capacidad de movilización que adquirió en ese período y reforzó posteriormente. Como muy convincentemente señaló en su libro Juan Sebastián Califa (2014), el debate sobre las universidades "libres", la defensa del monopolio estatal en la concesión de los títulos 
habilitantes puesta en cuestión por el artículo 28 del mismo decreto 6.403, el hecho de que, aún reconociendo la participación estudiantil, el nuevo ordenamiento universitario estableciese la hegemonía profesoral en lugar del gobierno tripartito igualitario y, finalmente, la politica antipopular de la "Libertadora", provocaron progresivamente la ruptura de los estudiantes reformistas con las autoridades. Posteriormente, los episodios del conflicto de la llamada "Laica o Libre", relacionada con la autorización concreta para el funcionamiento de las universidades privadas, la crisis del desarrollismo y sobre todo la Revolución Cubana acentuaron los procesos de radicalización hacia la izquierda de las organizaciones gremiales.

En todo este proceso hubo un rasgo de las acciones y estrategias estudiantiles que inauguró también estructuralmente el peronismo. Se trató de la articulación, intima y estrecha, entre las reivindicaciones y exigencias corporativas con los posicionamientos en relación con la política nacional. Ya no hubo margen para escindirlas y asumirlas en forma independiente, como había sucedido en los 20 y en alguna medida también en los 30 . Las actas de los consejos de gobierno universitario muestran el activo y profundo compromiso de representantes estudiantiles y dirigentes gremiales con las luchas de sectores obreros e intelectuales a nivel nacional e internacional. A menudo el tratamiento de estos temas en los consejos era obturado por la presión estudiantil para involucrar a las instituciones en reivindicaciones y luchas más amplias, relacionadas con la politica nacional e internacional.

El peronismo entonces y luego los efectos de la Guerra Fría inauguraron una nueva etapa en la relación entre movimiento estudiantil y acción política. El primero vio en las universidades esencialmente un foco opositor e intentó asegurar su neutralidad en el campo político. A su vez, el régimen universitario que concibió la "Revolución Libertadora" procuró avanzar en la construcción de una universidad autónoma, recuperando y fortaleciendo prácticas e instituciones que, en parte, reconocian sus orígenes en el movimiento de 1918. Pero era imposible asegurar la autonomía en un país signado por la inestabilidad politica provocada, entre otros factores, por la exclusión del escenario institucional de la fuerza política mayoritaria. La irrupción de la Guerra Fría y la percepción de la universidad como un foco revolucionario limitó todavía más la posibilidad de la autonomía.

En este escenario de radicalización y polarización creciente, hay por supuesto otros elementos. En principio, que estos procesos tuvieron lugar en un escenario caracterizado por el crecimiento sustantivo del número de estudiantes y por los cambios subsiguientes en su composición social. Los procesos de masificación además provocaron que los títulos perdieran progresivamente el valor que detentaban desde principio de 
siglo y que ya no estuviesen en condiciones de asegurar, en los mismos términos, los procesos de movilidad social (Portantiero, 1978). La extensión y masificación del sistema universitario también provocó cambios en sus vertientes politicas e ideológicas. Aún cuando las versiones que insisten en una peronización progresiva del movimiento estudiantil desde mediados de los 60 merecen ser puestas en cuestión (Millán, 2016: 49-64), las opciones politicas e ideológicas del estudiantado se volvieron durante estos años más complejas y diversas, profundizando un proceso que venía desde tiempos del primer peronismo. En parte esto ese explica por la aparición y el crecimiento de nuevos núcleos estudiantiles. La extensión del sistema universitario y creación de nuevas universidades, privadas primero, provinciales en algunos casos y nacionales sobre todo desde fines de los años 60, explica en parte este nuevo escenario. El reformismo, aún hegemónico en gran parte del movimiento estudiantil, pasó a ser contrarrestado por otras expresiones. Al humanismo que a principios de los 60 llegó a imponer dos rectores en la UBA, se sumó, sobre todo por su peso en el interior y el Litoral, el integralismo que congregó a grupos católicos que compartieron los procesos de radicalización de vastos sectores religiosos de los años 60. Pero el reformismo mismo se dividió en diversas expresiones, en parte como resultado de la aparición de nuevas vertientes de izquierda. El surgimiento del FAUDI, brazo universitario del Partido Comunista Revolucionario, una escisión del PC que poco después se orientó hacia el maoísmo, puede leerse en este sentido. Pero también pueden incluirse aquí el crecimiento de las agrupaciones relacionadas con las distintas vertientes del socialismo, el de las diversas líneas internas del radicalismo, el de la llamada izquierda nacional o incluso el de sectores que adoptarian más tarde la lucha armada. La diversificación y "pluralización" de la izquierda universitaria constituye entonces un fenómeno fundamental para el análisis de la trayectoria del movimiento estudiantil durante estos años.

\section{Reflexiones finales}

La percepción de los universitarios y del movimiento estudiantil como una amenaza sustantiva al orden social y político en el marco de la creciente influencia de la Doctrina de la Seguridad Nacional se impuso progresivamente en los años 60. Estas ideas explican la intervención a las universidades y, por supuesto también, la política represiva de la dictadura del 76. La universidad pasó a ser percibida como un núcleo subversivo y como un auténtico "nido de comunistas". El creciente compromiso de las organizaciones oficiales estudiantiles con los procesos de transformación revolucionaria alimentó estas creencias. El VIII Congreso de la FUA, celebrado en diciembre de 1967, en el momento 
más sólido del régimen de la "Revolución Argentina", se pronunció a favor de la lucha por la autonomía y el cogobierno. Pero sus consideraciones estuvieron ligadas estructuralmente a un diagnóstico y a una propuesta sobre la situación política nacional e internacional cuyos ejes estaban situados en la nacionalización de las ramas de la industria y los servicios en manos de monopolios extranjeros, en la ruptura con los organismos financieros internacionales, en la reforma agraria y en la destrucción del aparato represivo.

La trayectoria del movimiento estudiantil desde finales del siglo XIX hasta los años 60 revela el peso decisivo que la experiencia del peronismo tuvo en el involucramiento activo y estructural del movimiento estudiantil en la vida política argentina. Aquel dejó de ser parcial, episódico o limitado a algunas vertientes específicas. A la vez, galvanizó la constitución de la identidad reformista, aun cuando esta se expresase a través de diversas agrupaciones y se fragmentase en distintas expresiones gremiales y políticas. El reformismo se consolidó así como un factor central de la identidad estudiantil, aun cuando estuviese cuestionado por diversas vertientes políticas. Constituyó, como en los 20, un gran marco que abarcaba a sectores con orientaciones políticas distintas en la arena nacional pero que, en los aspectos universitarios, se identificaron con los principios de autonomía, cogobierno y laicismo y luego también con la defensa de la gratuidad, el aumento del presupuesto universitario y la solidaridad con la clase obrera.

Los años que siguieron al peronismo y sobre todo los 60 fueron también los de la ruptura del consenso liberal que había signado a la Argentina de las primeras décadas del siglo. En el marco de la Guerra Fría y bajo el impacto de los movimientos estudiantiles, que tuvieron expresión contundente en la participación en el Cordobazo, los sectores dominantes vieron a los estudiantes como vectores fundamentales de la alteración revolucionaria de ese orden social. El fin trágico de muchos de los militantes estudiantiles, tanto universitarios como secundarios, desde 1974, y sobre todo desde marzo de 1976, expresa claramente el nuevo estado de situación.

\section{Bibliografia}

Agosti, Héctor (1965), "Los recuerdos actuales", en Héctor Agosti, Para una politica de la cultura, Buenos Aires: Procyon, pp. 95-105.

Agulla, Juan Carlos (1968), Eclipse de una aristocracia, Buenos Aires: Libera. Almaraz, Roberto, Manuel Corchon y Rómulo Zemborain (2001), Aquí FUBA, Buenos Aires: Planeta.

Becher, Emilio (1906), "La oligarquía universitaria", reproducido en Emilio 
Becher, Diálogo de las sombras y otras páginas, Buenos Aires: Instituto de Literatura Argentina, Facultad de Filosofia y Letras, 1938, pp. 167-172. Brignardello, Luisa (1972), El movimiento estudiantil argentino, Buenos Aires: Macchi.

Bustelo, Natalia (2015), La reforma universitaria desde sus grupos y revistas: Una reconstrucción de los proyectos y las disputas del movimiento estudiantil porteño de las primeras décadas del siglo XX (1914-1928), tesis de doctorado, Facultad de Humanidades y Ciencias de la Educación, Universidad Nacional de La Plata. Disponible en: http://www. memoria.fahce.unlp.edu.ar/tesis/te.1307/te.1307.pdf. Consultada el 23 de febrero de 2017.

Califa, Juan (2014), Reforma y revolución. La radicalización politica del movimiento estudiantil en la UBA, 1943-1966, Buenos Aires: Eudeba.

Carreño, Luciana (2017), "Pobrecitos jovencitos sin sexo y sin seso. Formas y modelos de vida estudiantil bajo la crítica de los reformistas de izquierda en la Universidad de Buenos Aires (1917-1921)", en Izquierdas, n 32 , pp. 79-106.

Dickmann, Enrique (1930), Recuerdos de un militante socialista, Buenos Aires: La Vanguardia.

Hurtado, Gustavo (1990), Estudiantes: Reforma y revolución, Buenos Aires: Cartago.

James, Daniel (1987), “17 y 18 de octubre de 1945: el peronismo, la protesta de masas y la clase obrera argentina", Desarrollo Económico, n ${ }^{\circ} 107$, Buenos Aires, pp. 445-461.

Kleiner, Bernardo (1964), 20 años de movimiento estudiantil reformista, Buenos Aires: Platina.

Levenberg, Rubén y Daniel Merolla (1988), Un solo grito: crónica del movimiento estudiantil universitario, 1918-1988, Buenos Aires: FUA.

Millán, Mariano (2016), "La Juventud Universitaria Peronista en las memorias de la militancia estudiantil reformista y marxista de la UBA, 19731976", en Historia, Voces y Memoria, n 10, pp. 49-63.

Moyano, Julio (2010), "El clivaje entre clericales y liberales en la política cordobesa entre 1890 y 1930. Sus alcances y límites como causa de alianzas y conflictos entre la dirigencia”, en César Tcach (coord), Córdoba bicentenaria. Claves de su historia contemporánea, Córdoba: Centro de Estudios Avanzados, pp. 107-155.

Portantiero, Juan Carlos (1978), Estudiantes y politica en América Latina. 1918-1938: el proceso de la Reforma universitaria, México: Siglo XXI.

Roca, Deodoro (2008), "La Reforma no será posible sin una "Reforma Social", Entrevista del Diario Córdoba del 15 de junio de 1936" [1936], en Deodoro Roca, Obra reunida. I: Cuestiones universitarias, Córdoba, Universidad Nacional de Córdoba, pp. 121-122.

Romero, Ricardo (1998), La lucha continúa. El movimiento estudiantil argentino en el siglo $X X$, Buenos Aires: Eudeba. 
Villalobos Domínguez, Cándido (1919), Evitemos la guerra social, Buenos Aires: Tor.

Walter, Richard (1968), Student Politics in Argentina, Nueva York-Londres: Basic Book.

$$
* * *
$$

Titulo: The Argentine student movement: contributions for a global vision of its evolution in the 20th century

Resumen: El objetivo de este artículo es presentar una sintesis de la evolución del movimiento estudiantil desde principios del siglo XX hasta los años 60. Se pone énfasis especialmente en el estudio de la Reforma, en el impacto del peronismo y los vínculos entre acción gremial y política.

Palabras Clave: universidad - estudiantes - reforma - peronismo

Abstract: The aim of this article is to present a synthesis of the evolution of the student movement from the beginning of the 20th century up to the 1960s. Special emphasis is placed on the study of the Reform movement, the impact of Peronismo and the links between union and political action.

Keywords: university - students - reform - peronismo

Recepción: 20 de febrero de 2018. Aprobación: 5 de marzo de 2018. 